\title{
Prognostic significance of insulin growth factor-I receptor and insulin growth factor binding protein-3 expression in primary breast cancer
}

\author{
JUN HO KIM ${ }^{1 *}$, YOUNG HYE CHO ${ }^{2 *}$, YONG LAI PARK ${ }^{1}$, JIN HEE SOHN ${ }^{2}$ and HEE SUNG KIM ${ }^{2}$ \\ Departments of ${ }^{1}$ Surgery and ${ }^{2}$ Pathology, Kangbuk Samsung Hospital, \\ Sungkyunkwan University School of Medicine, Seoul 110-746, Korea
}

Received September 23, 2009; Accepted November 18, 2009

DOI: $10.3892 /$ or_00000724

\begin{abstract}
We analyzed insulin-like growth factor receptor I (IGF-IR) and insulin growth factor binding protein-3 (IGFBP-3) expression with respect to overall survival and relapse-free survival (RFS) in 460 patients with primary invasive breast cancer using immunohistochemistry. IGF-IR expression had a significant positive correlation with positive estrogen receptor (ER), positive progesterone receptor (PR) and $\mathrm{Bcl}-2$ expression. Univariate analysis showed significantly better overall survival $(\mathrm{p}=0.000)$ and RFS $(\mathrm{p}=0.004)$, in the IGF-IR-positive group. Multivariate analysis showed a significant reduction in relative risk for overall survival $(\mathrm{p}=0.019, \mathrm{HR}=0.221,95 \% \mathrm{CI}=0.062-0.780)$ and $\mathrm{RFS}$ $(\mathrm{p}=0.026, \mathrm{HR}=0.462,95 \% \mathrm{CI}=0.234-0.913)$ in the IGF-IRpositive group. IGF-IR expression in primary breast cancer is an independent favorable prognostic factor. IGFBP-3 expression in breast cancer is associated with poor outcome.
\end{abstract}

\section{Introduction}

High blood IGF-I levels are associated with an increased risk of breast cancer, especially in premenopausal women (1). Most of the effects of IGF-I result from its activation of the IGF-IR. The insulin-like growth factors (IGFs) are mitogens that play a pivotal role in regulating cell proliferation, differentiation, and apoptosis. The effects of IGFs are mediated through the IGF-I receptor. The IGFs are

Correspondence to: Dr Hee Sung Kim, Department of Pathology, Kangbuk Samsung Hospital, No. 108 Pyung-Dong, Jongro-Ku, Seoul 110-746, South Korea

E-mail: heesung1.kim@samsung.com

*Contributed equally

Abbreviations: IGF-IR, insulin-like growth factor receptor I; IGFBP-3, insulin growth factor binding protein-3; ER, estrogen receptor; $\mathrm{PR}$, progesterone receptor; $\mathrm{BMI}$, body mass index; $\mathrm{BCO}$, breast conserving surgery; HER2, human epidermal growth factor receptor 2; EGFR, epithelial growth factor receptor; VEGF, vascular endothelial growth factor; OS, overall survival; RFS, relapse-free survival; RR, relative risk; CI, confidence interval

Key words: breast cancer, IGF-IR, IGFBP-3, immunocytochemistry modulated by a family of six high-affinity IGF binding proteins, of which IGFBP-3 predominates in serum and is upregulated in breast cancer cell lines, including breast epithelium. Both IGFs (IGF-I and IGF-II) have a preferential stromal expression and together with epithelial IGFBP-3 have a significant paracrine influence on breast epithelial growth (2). IGFBP-3 is found not only to regulate the mitogenic action of IGFs but also to inhibit their antiapoptotic effect. Besides its IGF-dependent function, IGFBP3 also has an IGF independent inhibitory effect on cell growth (3).

The IGF-IR activation has been implicated in the malignant progression of several types of human cancer $(4,5)$. IGF-IR has been found to be significantly expressed and highly activated in breast cancer, and its prognostic and predictive value in clinical samples is of interest (6-8). However, the correlation between IGF-IR overexpression and prognosis or other clinicopathological parameters has not been confirmed $(9,10)$. Detection of IGFBP-3 in breast tissue has been reported to have no association with diseasefree survival and to have either no association with overall survival or an association with increased risk of death; the latter association was independent of other prognostic factors $(11,12)$.

We analyzed the immunohistochemical expression of IGF-IR and IGFBP3 with clinicopathological variables and the correlation with overall survival and relapse-free survival (RFS) in 460 patients with invasive breast cancer.

\section{Patients and methods}

Patients. Four hundred and sixty patients (median age 46; age range, 23-84 years) with breast carcinomas were included in this study. The patients underwent breast cancer surgery at the National Cancer Center (Gyeonggi, Korea) and at Kangbuk Samsung Hospital (Seoul, Korea) between 2000 and 2006. Three hundred and twenty-eight of the patients with breast cancer underwent survival analysis. The mean follow-up was 53 (range 7-85) months. The immunohistochemical expression of IGF-IR and IGFBP-3 was analyzed in 460 patients with breast cancer. The RFS was calculated as the period from surgery until the date of the first recurrence. The study was submitted and met the guidelines of the local institutional review committees. 
Table I. Correlation for IGF-IR and IGFBP-3 expression with clinicopathological variables in primary breast cancer.

\begin{tabular}{|c|c|c|c|c|c|c|c|c|c|c|c|}
\hline & \multirow[b]{3}{*}{ Total } & \multicolumn{5}{|c|}{ IGF-IR } & \multicolumn{5}{|c|}{ IGFBP-3 } \\
\hline & & \multicolumn{2}{|c|}{ Negative } & \multicolumn{2}{|c|}{ Positive } & \multirow[b]{2}{*}{ P-value } & \multicolumn{2}{|c|}{ Negative } & \multicolumn{2}{|c|}{ Positive } & \multirow[b]{2}{*}{ P-value } \\
\hline & & $\mathrm{n}$ & $\%$ & $\mathrm{n}$ & $\%$ & & $\mathrm{n}$ & $\%$ & $\mathrm{n}$ & $\%$ & \\
\hline \multicolumn{12}{|l|}{ Age } \\
\hline$<50$ & 275 & 131 & 58.0 & 144 & 63.4 & \multirow[t]{2}{*}{0.233} & 147 & 62.8 & 111 & 61.7 & \multirow[t]{2}{*}{0.810} \\
\hline$\geq 50$ & 178 & 95 & 42.0 & 83 & 36.6 & & 87 & 37.2 & 69 & 38.3 & \\
\hline \multicolumn{12}{|l|}{ BMI } \\
\hline$<25$ & 162 & 79 & 35.0 & 83 & 36.6 & \multirow{2}{*}{0.744} & 82 & 35.0 & 69 & 38.3 & \multirow[t]{2}{*}{0.575} \\
\hline$\geq 25$ & 56 & 26 & 11.5 & 30 & 13.2 & & 32 & 13.7 & 19 & 10.6 & \\
\hline \multicolumn{12}{|l|}{ Operation } \\
\hline $\mathrm{BCO}$ & 95 & 47 & 20.8 & 48 & 21.1 & \multirow[t]{2}{*}{0.271} & 33 & 14.1 & 51 & 28.3 & \multirow[t]{2}{*}{0.001} \\
\hline Mastectomy & 303 & 157 & 69.5 & 146 & 64.3 & & 177 & 75.6 & 106 & 58.9 & \\
\hline \multicolumn{12}{|l|}{ Histological grade } \\
\hline 1 & 101 & 42 & 19.6 & 59 & 27.8 & \multirow[t]{3}{*}{0.014} & 56 & 25.0 & 33 & 19.9 & \multirow[t]{3}{*}{0.444} \\
\hline 2 & 173 & 82 & 38.3 & 91 & 42.9 & & 89 & 39.7 & 67 & 40.4 & \\
\hline 3 & 152 & 90 & 42.1 & 62 & 29.2 & & 79 & 35.3 & 66 & 39.8 & \\
\hline \multicolumn{12}{|l|}{$\mathrm{T}$} \\
\hline $\mathrm{T} 1$ & 223 & 108 & 47.8 & 115 & 50.7 & \multirow[t]{4}{*}{0.211} & 103 & 44.0 & 96 & 53.3 & 0.204 \\
\hline $\mathrm{T} 2$ & 197 & 96 & 42.5 & 101 & 44.5 & & 112 & 47.9 & 72 & 40.0 & \\
\hline $\mathrm{T} 3$ & 29 & 20 & 8.8 & 9 & 4.0 & & 18 & 7.7 & 10 & 5.6 & \\
\hline $\mathrm{T} 4$ & 4 & 2 & 0.9 & 2 & 0.9 & & 1 & 0.4 & 2 & 1.1 & \\
\hline $\mathrm{N}$ & & & & & & & & & & & \\
\hline No & 265 & 127 & 56.2 & 138 & 60.8 & 0.025 & 128 & 54.7 & 115 & 63.9 & 0.117 \\
\hline N1 & 106 & 47 & 20.8 & 59 & 26.0 & & 57 & 24.4 & 39 & 21.7 & \\
\hline $\mathrm{N} 2$ & 38 & 27 & 11.9 & 11 & 4.8 & & 27 & 11.5 & 10 & 5.6 & \\
\hline N3 & 44 & 25 & 11.1 & 19 & 8.4 & & 22 & 9.4 & 16 & 8.9 & \\
\hline ER & & & & & & & & & & & \\
\hline Negative & 206 & 148 & 66.1 & 58 & 25.6 & 0.000 & 103 & 44.0 & 88 & 49.4 & 0.274 \\
\hline Positive & 245 & 76 & 33.9 & 169 & 74.4 & & 131 & 56.0 & 90 & 50.6 & \\
\hline PR & & & & & & & & & & & \\
\hline Negative & 221 & 152 & 67.9 & 69 & 30.4 & 0.000 & 106 & 45.3 & 95 & 53.1 & 0.117 \\
\hline Positive & 230 & 72 & 32.1 & 158 & 69.6 & & 128 & 54.7 & 84 & 46.9 & \\
\hline HER2 & & & & & & & & & & & \\
\hline No overexpression & 359 & 154 & 68.8 & 205 & 90.3 & 0.000 & 196 & 83.8 & 134 & 74.9 & 0.025 \\
\hline Overexpression & 92 & 70 & 31.3 & 22 & 9.7 & & 38 & 16.2 & 45 & 25.1 & \\
\hline Hormone therapy & & & & & & & & & & & \\
\hline No & 88 & 63 & 37.7 & 25 & 15.6 & 0.000 & 34 & 19.5 & 47 & 36.2 & 0.001 \\
\hline Yes & 239 & 104 & 62.3 & 135 & 84.4 & & 140 & 80.5 & 83 & 63.8 & \\
\hline Chemotherapy & & & & & & & & & & & \\
\hline No & 59 & 19 & 11.4 & 40 & 25.0 & 0.001 & 31 & 17.8 & 23 & 17.7 & 0.978 \\
\hline Yes & 268 & 148 & 88.6 & 120 & 75.0 & & 143 & 82.2 & 107 & 82.3 & \\
\hline
\end{tabular}

Standard histopathological examination included the type of cancer and the pathological tumor stage assessed according to the criteria established by the 6th edition of the AJCC Staging Manual (13).

$H \& E$ and immunohistochemical staining. All of the tissues obtained from patients were routinely fixed in $10 \%$ buffered formalin and embedded in paraffin blocks. Tissue array blocks containing breast cancer tissues (6 $\mathrm{mm}$ in diameter) were produced from enrolled cases. The tissue microarray blocks were sectioned at a thickness of $4-\mu \mathrm{m}$ and were processed for immunohistochemical staining. Paraffin was removed from the tissue sections with xylene. The sections were rehydrated with graded ethanol and immersed in Tris-buffered saline. The expression of IGF-IR, IGFBP-3, and VEGF was determined by immunohistochemical staining using rabbit poly- 
Table II. Correlation for IGF-IR and IGFBP-3 expression with breast cancer-related biomarkers.

\begin{tabular}{|c|c|c|c|c|c|c|c|c|c|c|}
\hline & \multicolumn{5}{|c|}{ IGF-IR } & \multicolumn{5}{|c|}{ IGFBP-3 } \\
\hline & \multicolumn{2}{|c|}{ Negative } & \multicolumn{2}{|c|}{ Positive } & \multirow[b]{2}{*}{ P-value } & \multicolumn{2}{|c|}{ Negative } & \multicolumn{2}{|c|}{ Positive } & \multirow[b]{2}{*}{ P-value } \\
\hline & $\mathrm{n}$ & $\%$ & $\mathrm{n}$ & $\%$ & & $\mathrm{n}$ & $\%$ & $\mathrm{n}$ & $\%$ & \\
\hline \multicolumn{11}{|l|}{ EGFR } \\
\hline Negative & 179 & 83.6 & 192 & 91.4 & 0.015 & 196 & 87.5 & 153 & 89.0 & 0.658 \\
\hline Positive & 35 & 16.4 & 18 & 8.6 & & 28 & 12.5 & 19 & 11.0 & \\
\hline \multicolumn{11}{|l|}{ VEGF } \\
\hline Negative & 135 & 63.1 & 151 & 71.9 & 0.053 & 150 & 66.7 & 122 & 69.7 & 0.517 \\
\hline Positive & 79 & 36.9 & 59 & 28.1 & & 75 & 33.3 & 53 & 30.3 & \\
\hline \multicolumn{11}{|l|}{$\mathrm{Bcl} 2$} \\
\hline Negative & 134 & 62.0 & 56 & 25.3 & 0.000 & 91 & 39.6 & 86 & 49.1 & 0.054 \\
\hline Positive & 82 & 38.0 & 165 & 74.7 & & 139 & 60.4 & 89 & 50.9 & \\
\hline \multicolumn{11}{|l|}{ p53 } \\
\hline Negative & 141 & 65.6 & 181 & 81.2 & 0.000 & 169 & 73.8 & 126 & 71.6 & 0.620 \\
\hline Positive & 74 & 34.4 & 42 & 18.8 & & 60 & 26.2 & 50 & 28.4 & \\
\hline \multicolumn{11}{|l|}{ Ki-67 } \\
\hline Low $(<10 \%)$ & 134 & 66.7 & 154 & 72.6 & 0.186 & 157 & 71.4 & 110 & 65.5 & 0.215 \\
\hline High $(\geq 10 \%)$ & 67 & 33.3 & 58 & 27.4 & & 63 & 28.6 & 58 & 34.5 & \\
\hline \multicolumn{11}{|l|}{ IGFBP-3 } \\
\hline Negative & 111 & 53.9 & 123 & 59.4 & 0.256 & 234 & 100 & 0 & 0 & \\
\hline Positive & 95 & 46.1 & 84 & 40.6 & & 0 & 0 & 180 & 100 & \\
\hline \multicolumn{11}{|l|}{ IGF-IR } \\
\hline Negative & 226 & 100 & 0 & 0 & & 111 & 47.4 & 95 & 53.1 & 0.256 \\
\hline Positive & 0 & 0 & 227 & 100 & & 123 & 52.6 & 84 & 46.9 & \\
\hline
\end{tabular}

clonal antibodies against IGF-IRß (1:100 dilution; Cell Signaling Technology, Danvers, MA), goat polyclonal antibodies against IGFBP-3 (C-19, Santa Cruz Biotechnology, Inc., Santa Cruz, CA) and mouse monoclonal antibodies against VEGF (C-1, 1:100 dilution; Santa Cruz Biotechnology). A biotinylated anti-mouse antibody was used as a secondary antibody, and streptavidin horseradish peroxidase (Zymed Laboratories, San Francisco, CA, USA) was used following the instructions provided by the manufacturer. The sections were counterstained in Mayer's hematoxylin, dehydrated and cleared, and the sections were mounted for examination (Fig. 1).

Interpretation of immunohistochemistry findings. Immunoreactivity for IGF-IR was evaluated in the neoplastic epithelial cells using a combined scoring system based on the sum of the staining intensity ( 0 , negative staining; 1 , weak; 2 , intermediate; and 3, strong staining) and the percentage of positive cells $(0,0 \% ; 1,1-25 \% ; 2,26-50 \%$; and $3,>50 \%)$. Scores from 0-3 were given for the staining intensity and the percentage of positive cells, these then being added together to obtain the overall score with a maximum of 6 . A score of 0 (negative or low expression) was considered as negative with respect to IGF-IR staining, while scores of 2-6 (high expression) were considered as positive (14).

IGFBP-3 expression was scored as follows: the staining intensity in the cytoplasm only was evaluated from 0 to 3 (representing none to strong staining, respectively) and the \% cells in each intensity was obtained. The overall score was determined as follows: overall score $=[(\%$ cells with visual score 1$) \times 1]+[(\%$ cells with visual score 2$) \times 2]+[(\%$ cells with visual score 3$) \times 3$ ]; expression was positive if the score was $>5(15)$.

A cut-off value of $10 \%$ of the positively-stained nuclei was used to define estrogen receptor (ER) and progesterone receptor (PR) positivity. Cytoplasmic staining with an intensity $>10 \%$ of the tumor cells was scored as positive for Bcl-2. Membranous staining for HER2 was scored as follows: 0, no staining or membranous staining in $<10 \%$ of the cells; $1+$, faint incomplete staining in $10 \%$ of the cells; $2+$, weak-tomoderate complete staining in $10 \%$ of the cells; and $3+$, strong complete staining in $10 \%$ of the cells. HER 2 overexpression was defined as a score of 3+. Cells staining for Ki-67 and p53 were expressed as a percentage. The Ki-67 labeling index was graded as low if the number of positive cells was $<10 \%$ and high if the number of positive cells was $\geq 10 \%$. p53 was scored as positive if $>10 \%$ of the cells were positive with a strong intensity.

Statistical analysis. Statistical analysis was performed with SPSS software, version 15.0 (SPSS, Inc., Chicago, IL, USA). Pearson's $\chi^{2}$ test was used to examine the correlation between the variables. Kaplan-Meier curves were plotted from data of the overall survival and RFS. The Cox proportional regression hazard model was performed with variables, including histological grade, ER expression, PR expression, HER2 over- 


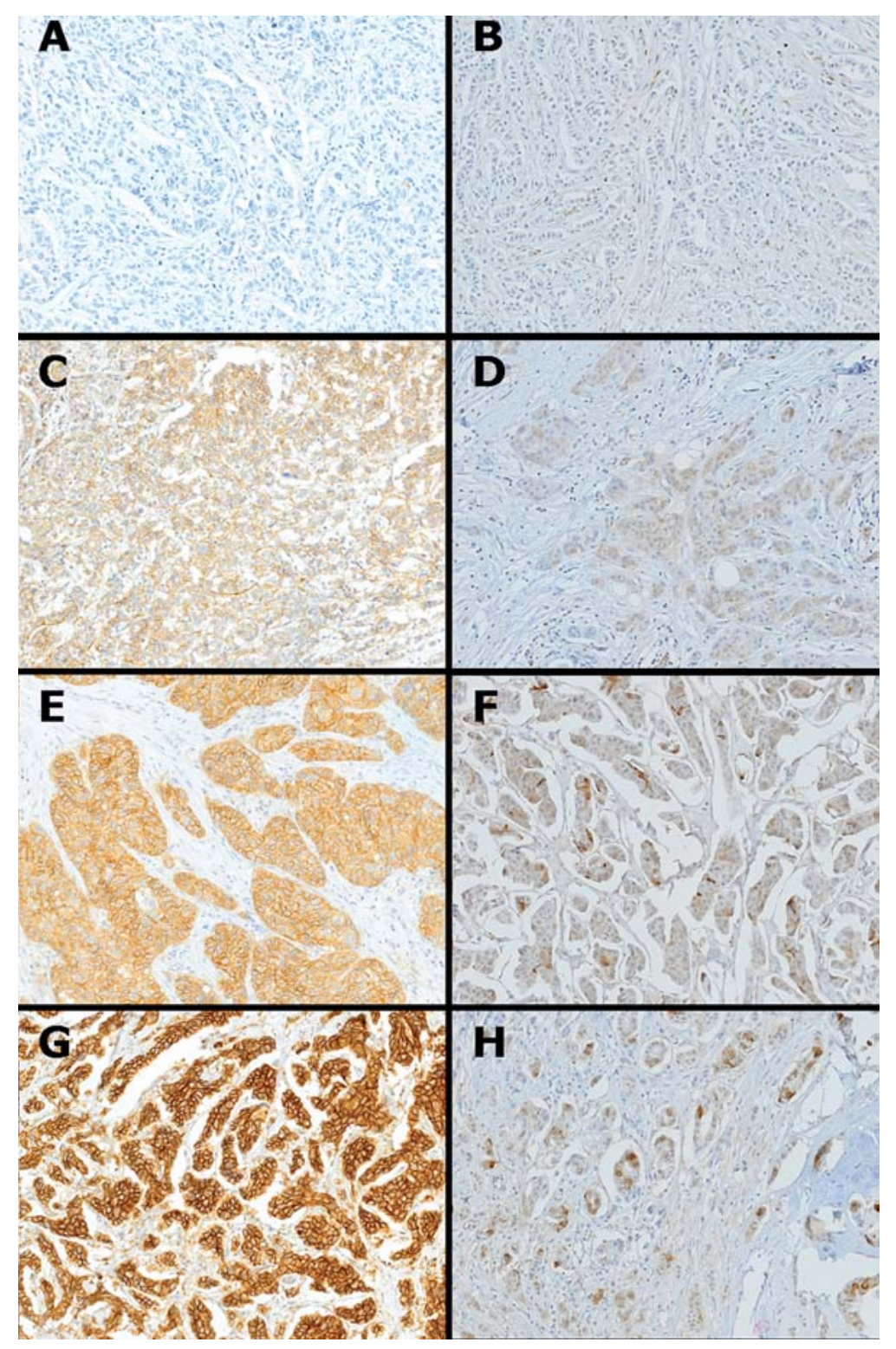

Figure 1. Immunohistochemical detection of IGF-IR and IGFBP-3 in breast cancer tissues. (A, C, E and G) IGF-IR. (B, D, F and H) IGFBP-3. (A and B, negative; $\mathrm{C}$ and $\mathrm{D}$, weak positive; $\mathrm{E}$ and $\mathrm{F}$, moderate positive; $\mathrm{G}$ and $\mathrm{H}$, strong positive).

expression, IGF-IR expression, IGFBP-3 expression, hormone therapy and chemotherapy for survival analysis. A p-value $<0.05$ was considered statistically significant.

\section{Results}

Clinicopathological correlation of IGF-IR and IGFBP-3 expression in breast cancer tissue. The clinicopathological characteristics of the enrolled patients and correlation for IGF-IR and IGFBP-3 expression is shown in Table I. Positive membrano-cytoplasmic immunoreactivity for IGF-IR existed in $50.1 \%$ of the cases (227 of 453). Cytoplasmic expression for IGFBP-3 was noted in $43.5 \%$ (180 out of 414). IGF-IR expression had a significant correlation with ER, PR, and a significant inverse correlation with histological grade, $\mathrm{N}$ stage and HER2 overexpression. IGFBP-3 expression had a significant correlation with HER2 overexpression. However, no significant correlation was noted for age, BMI, or T stage with IGF-IR or IGFBP-3 expression. In the comparison with expression of breast cancer-related markers, the expression of IGF-IR correlated with $\mathrm{Bcl}-2$ expression $(\mathrm{p}=0.000)$ and was inversely correlated with p53 ( $\mathrm{p}=0.000)$ and EGFR expression $(\mathrm{p}=0.015)$; no significant correlation was noted with IGFBP-3 expression (Table II).

Univariate analysis of IGF-IR and IGFBP-3 expression on overall survival and RFS in breast cancer patients. Based on the univariate Kaplan-Meier analysis of 326 cases, the clinicopathological variables with a prognostic value included histological grade, T stage, $\mathrm{N}$ stage, HER2 status, and Bcl-2, p53, or Ki-67 expression for overall survival; T stage, N stage, HER2 status, and p53 expression for relapse-free survival (RFS) (data not shown).

Kaplan-Meier survival analyses showed a significantly better overall survival $(\mathrm{p}=0.000)$ and RFS $(\mathrm{p}=0.004)$ in the IGF-IR-positive group compared to the IGF-IR-negative group. In contrast, IGFBP-3-positive group showed worse overall survival $(\mathrm{p}=0.057)$ and no difference in RFS compared to IGFBP-3-negative group (Fig. 2). We stratified the patients 
A

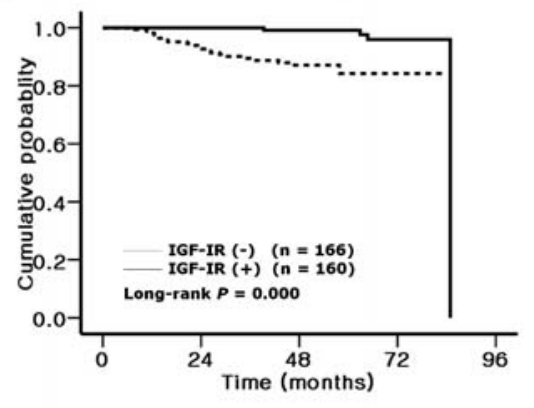

C

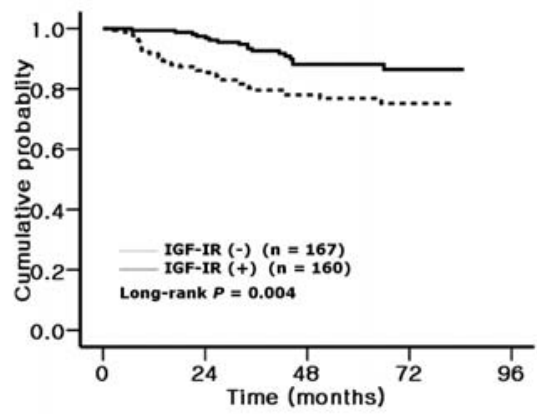

B

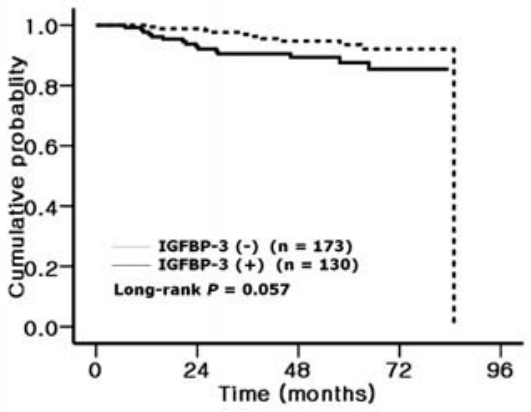

D

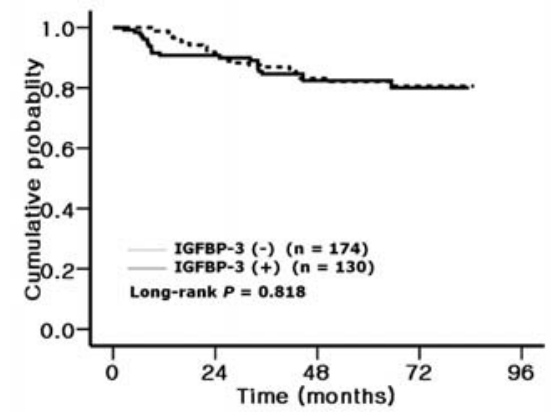

Figure 2. Overall survival (A) and RFS (B) according to IGF-IR; overall survival (C) and RFS (D) according to IGFBP-3 in patients with breast cancer.

A

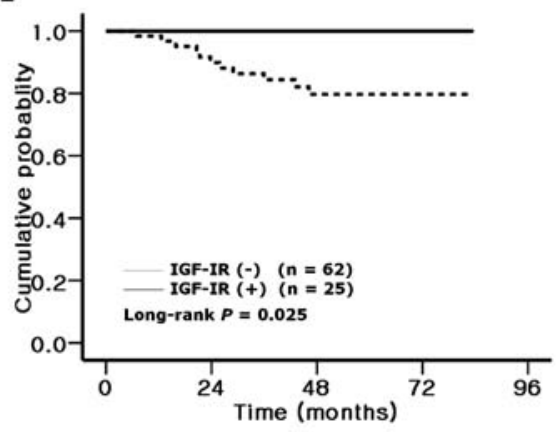

C

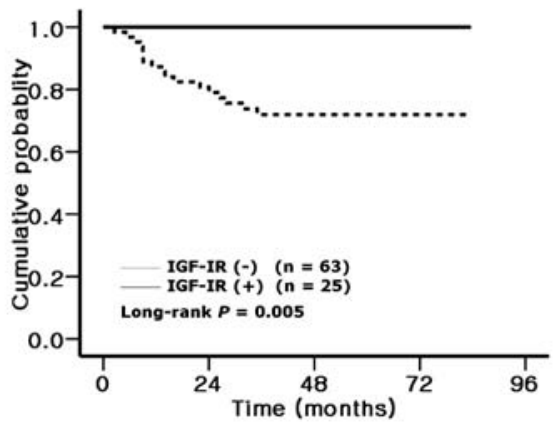

B

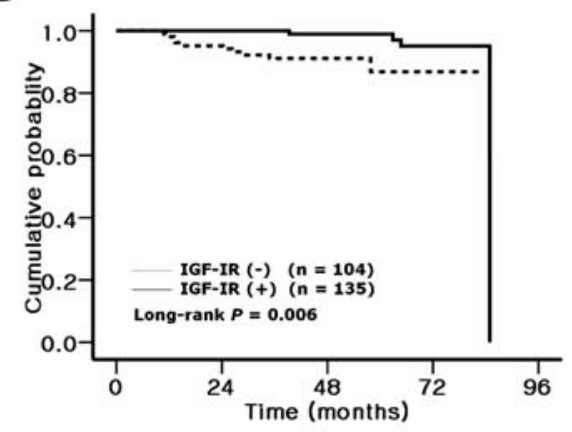

D

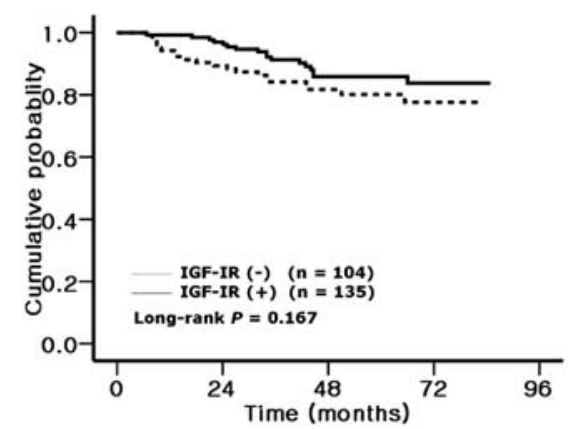

Figure 3. Overall survival and RFS in subgroup analyses by hormone therapy. Overall survival in (A) no hormone therapy, (B) hormone therapy; RFS in (C) no hormone therapy, (D) hormone therapy.

by whether they received hormone therapy or not. Both the patient groups with hormone therapy and without hormone therapy showed significant difference of overall survival. Between the patient groups with IGF-IR-positive and negative, a significant difference in RFS was noted in the patients without hormone therapy, not in the patients with hormone therapy (Fig. 3). The difference of 5-year overall survival by IGF-IR expression was greater in the group with hormone therapy $(20.3 \%)$ than without hormone therapy $(12.3 \%)$. The difference of 5-year RFS by IGF-IR expression was greater in the group with hormone therapy $(28.2 \%)$ than without hormone therapy (5.9\%, Fig. 3). 
Table III. Cox's proportional hazards regression models for overall survival and RFS.

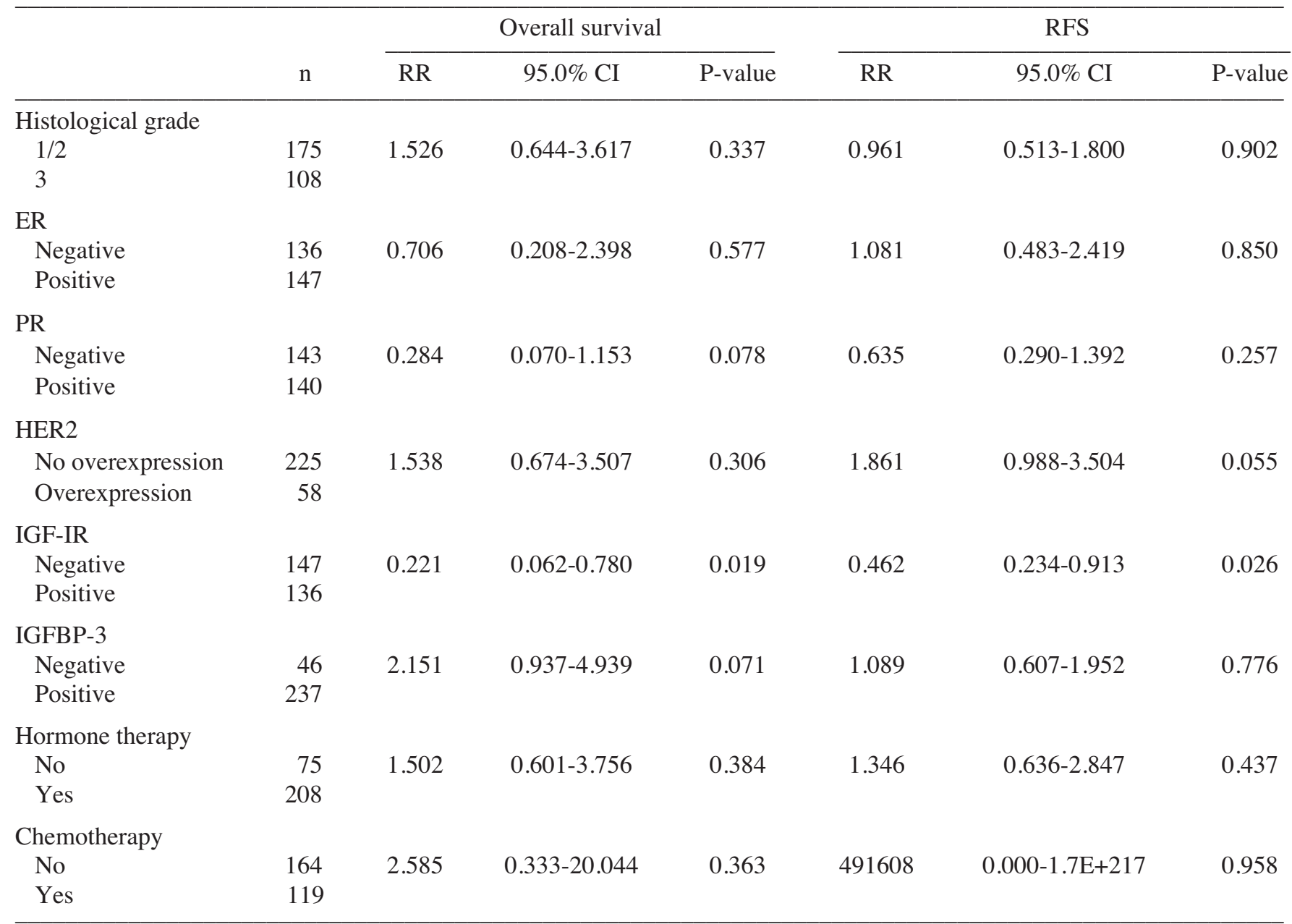

Multivariate analysis. A model of multivariate Cox proportional hazard analysis was performed with variables, including IGF-IR expression and IGFBP-3 expression (Table III). A model adjusted for histological grade, ER expression, PR expression, HER2 overexpression, IGF-IR expression, IGFBP-3 expression, hormone therapy and chemotherapy showed a significant reduction of relative risk by IGF-IR expression for overall survival $(\mathrm{p}=0.019, \mathrm{HR}=0.221,95 \%$ $\mathrm{CI}=0.062-0.780)$ and for RFS $(\mathrm{p}=0.026, \mathrm{HR}=0.462,95 \%$ $\mathrm{CI}=0.234-0.913$ ). However, no significant correlation was noted by IGFBP-3 expression for overall survival or RFS in this model (Table III).

\section{Discussion}

IGF-IR is overexpressed in colorectal cancer and synovial sarcoma, and its overexpression is associated with aggressive tumors $(16,17)$. Previous studies were not consistent regarding the intratumoral IGF-IR expression as a prognostic factor in primary breast cancer. Expression of IGF-IR was associated with a poor prognosis in the subgroup of ER-negative cancers (18), or to be without prognostic importance (8). Nielsen et al (19) noted IGF-IR immunostaining in $87 \%$ in breast cancer (615 of 707) and they reported that the expression of IGF-IR and urokinase plasminogen activator is associated with poor survival. Shin et al (20) reported the reduced mRNA expression of IGF-I and IGF-IR genes in breast tumor tissue compared to adjacent tissue and a correlation for poor overall and disease-free survival. Increased level of IGF-IR expression in breast cancer specimens is found to inhibit apoptosis, and was associated with an increased risk of relapse after radiation therapy (21). There are studies concordant with our results that reported that the expression of IGF-IR was associated with a better overall survival and RFS by immunoassay $(7,22)$. Our study strongly suggested that intratumoral IGF-IR expression is a significant prognostic factor and intratumoral IGFBP-3 expression is associated with a shorter overall survival in breast cancer by immunohistochemistry.

Shimizu et al (9) showed no correlation for IGF-IR expression and prognosis using antibody against IGF-I $\alpha$. IGF-IR is a tetramer composed of two extracellular $\alpha$-subunits $(130 \mathrm{kDa})$ and two transmembrane $\beta$-subunits $(90 \mathrm{kDa})$. The $\alpha$-subunit is extracellular, while the $\beta$-subunit is a transmembrane protein that has cytoplasmic tyrosine kinase activity. IGF-I binding to the extracellular domain stimulates tyrosine kinase activity, which in turn phosphorylates cytoplasmic components of an IGF-I-specific signal cascade leading to several biological effects, including cell growth (7). It should be noted that IGF-IR immunostaining with a single $\beta$-subunit antibody was diffusely cytoplasmic in most samples, in contrast to the expected membrane localization 
reported by Chott et al (23), who used two different $\alpha$-subunit antibodies.

IGF-IR ligands, IGF-I and IGF-II are strong mitogens for many hormone-dependent breast cancer cell lines and have been found in the epithelial and/or stromal component of breast tumors. During tumorigenesis, overexpression of IGF-IR is presumed to increase the cellular responsiveness to IGFs in terms of proliferation and inhibition of apoptosis (24). In breast cancer cells, estrogens enhance the mitogenic effect of IGF-I, induce expression of IGF-I, and stimulate production of IGF-IR (3). The interaction between estrogens and IGF is reciprocal. IGF-I enhances expression of estrogen receptor in breast cancer cells, and ER levels in breast tissue are associated with the levels of some IGFBPs (3).

Our results showed that IGF-IR could be an indication of the tamoxifen-resistance in the patients who received adjuvant hormone therapy, because the group with hormone therapy showed less survival gain by IGF-IR expression compared to the group without hormone therapy. One study for utilization of semi-quantitative immunohistochemistry of IGF-IR as one of the markers of intratumoral ER showed promising results for prediction of response to letrozole versus tamoxifen (25). They showed that the greatest benefit from aromatase inhibitor treatment was seen in patients with a high expression level of estrogen regulated proteins such as PR, Bcl-2 and IGF-IR reflecting a high intratumoral estrogen content and ER driven cell growth.

In cancer, IGFBPs regulate the action of IGFs. In most situations, the binding proteins suppress the mitogenic action of IGFs and promote apoptosis. However, because of the presence of IGFBP proteases, two in vitro studies have found that IGFBPs are able to stimulate the growth of cancer cells (17). Our study showed significant correlation for IGFBP-3 expression and HER2 overexpression. Although statistical significance was not obtained, a worse overall survival for IGFBP-3 positive group was noted.

In conclusion, the immunohistochemical expression of IGF-IR and IGFBP-3 suggested that IGF-IR expression is a favorable prognostic factor in breast cancer. In addition, IGF-IR expression is associated with tamoxifen-resistance. Prospective studies for utilization of IGF-IR expression with hormone therapy in primary breast cancer are warranted.

\section{Acknowledgements}

This work was supported by the Research funds from Kangbuk Samsung Hospital, Seoul, South Korea.

\section{References}

1. Renehan AG, Zwahlen M, Minder C, O'Dwyer ST, Shalet SM and Egger M: Insulin-like growth factor (IGF)-I, IGF binding protein-3, and cancer risk: systematic review and meta-regression analysis. Lancet 363: 1346-1353, 2004.

2. Sachdev D and Yee D: The IGF system and breast cancer. Endocr Relat Cancer 8: 197-209, 2001.

3. $\mathrm{Yu} \mathrm{H}$ and Rohan T: Role of the insulin-like growth factor family in cancer development and progression. J Natl Cancer Inst 92: 1472-1489, 2000

4. Steller MA, Delgado CH, Bartels CJ, Woodworth CD and Zou Z: Overexpression of the insulin-like growth factor-1 receptor and autocrine stimulation in human cervical cancer cells. Cancer Res 56: 1761-1765, 1996.
5. Cullen KJ, Yee D, Sly WS, et al: Insulin-like growth factor receptor expression and function in human breast cancer. Cancer Res 50: 48-53, 1990.

6. Foekens JA, Portengen H, Janssen M and Klijn JG: Insulin-like growth factor-1 receptors and insulin-like growth factor-1-like activity in human primary breast cancer. Cancer 63: 2139-2147, 1989.

7. Papa V, Gliozzo B, Clark GM, et al: Insulin-like growth factor-I receptors are overexpressed and predict a low risk in human breast cancer. Cancer Res 53: 3736-3740, 1993.

8. Foekens JA, Portengen H, van Putten WLJ, et al: Prognostic value of receptors for insulin-like growth factor 1, somatostatin, and epidermal growth factor in human breast cancer. Cancer Res 49: 7002-7009, 1989.

9. Shimizu C, Hasegawa T, Tani Y, et al: Expression of insulinlike growth factor 1 receptor in primary breast cancer: immunohistochemical analysis. Hum Pathol 35: 1537-1542, 2004.

10. Chong YM, Williams SL, Elkak A, Sharma AK and Mokbel K: Insulin-like growth factor 1 (IGF-1) and its receptor mRNA levels in breast cancer and adjacent non-neoplastic tissue. Anticancer Res 26: 167-173, 2006.

11. Yu H, Levesque MA, Khosravi MJ, Papanastasiou-Diamandi A, Clark GM and Diamandis EP: Insulin-like growth factorbinding protein-3 and breast cancer survival. Int J Cancer 79: 624-628, 1998

12. Rocha RL, Hilsenbeck SG, Jackson JG, et al: Insulin-like growth factor binding protein-3 and insulin receptor substrate1 in breast cancer: correlation with clinical parameters and disease-free survival. Clin Cancer Res 3: 103-109, 1997.

13. Greene FL, Page DL, Fleming ID, et al: AJCC Cancer Staging Manual, 2002.

14. Kostopoulos I, Arapantoni-Dadioti P, Gogas H, et al: Evaluation of the prognostic value of HER-2 and VEGF in breast cancer patients participating in a randomized study with dose-dense sequential adjuvant chemotherapy. Breast Cancer Res Treat 96: 251-261, 2006.

15. So A, Sinnemann S, Huntsman D, Fazli L and Gleave M: Knockdown of the cytoprotective chaperone, clusterin, chemosensitizes human breast cancer cells both in vitro and in vivo. Mol Cancer Ther 4: 1837-1849, 2005.

16. Hakam A, Yeatman TJ, Lu L, et al: Expression of insulinlike growth factor-1 receptor in human colorectal cancer Hum Pathol 30: 1128-1133, 1999

17. Xie Y, Skytting B, Nilsson G, Brodin B and Larsson O: Expression of insulin-like growth factor-1 receptor in synovial sarcoma: association with an aggressive phenotype. Cancer Res 59: 3588-3591, 1999.

18. Railo MJ, von Smitten K and Pekonen F: The prognostic value of insulin-like growth factor-I in breast cancer patients. Results of a follow-up study on 126 patients. Eur J Cancer 30A: 307-311, 1994.

19. Nielsen TO, Andrews HN, Cheang M, et al: Expression of the insulin-like growth factor I receptor and urokinase plasminogen activator in breast cancer is associated with poor survival: potential for intervention with 17-allylamino geldanamycin. Cancer Res 64: 286-291, 2004

20. Shin A, Ren Z, Shu XO, Cai Q, Gao YT and Zheng W: Expression patterns of insulin-like growth factor 1 (IGF-I) and its receptor in mammary tissues and their associations with breast cancer survival. Breast Cancer Res Treat 105: 55-61, 2007.

21. Turner BC, Haffty BG, Narayanan L, et al: Insulin-like growth factor-I receptor overexpression mediates cellular radioresistance and local breast cancer recurrence after lumpectomy and radiation. Cancer Res 57: 3079-3083, 1997.

22. Bonneterre J, Peyrat JP, Beuscart R and Demaille A: Prognostic significance of insulin-like growth factor 1 receptors in human breast cancer. Cancer Res 50: 6931-6935, 1990.

23. Chott A, Sun Z, Morganstern D, et al: Tyrosine kinases expressed in vivo by human prostate cancer bone marrow metastases and loss of the type 1 insulin-like growth factor receptor. Am J Pathol 155: 1271-1279, 1999

24. Helle SI: The insulin-like growth factor system in advanced breast cancer. Best Pract Res Clin Endocrinol Metab 18: 67-79, 2004.

25. Henriksen KL, Rasmussen BB, Lykkesfeldt AE, Moller S, Ejlertsen B and Mouridsen HT: An ER activity profile including ER, PR, Bcl-2 and IGF-IR may have potential as selection criterion for letrozole or tamoxifen treatment of patients with advanced breast cancer. Acta Oncol 48: 522-531, 2009. 